\title{
Wound healing: time to look for intelligent, 'natural' immunological approaches?
}

\author{
Olivier Garraud ${ }^{1,2^{*}}$, Wael N. Hozzein ${ }^{3,4}$ and Gamal Badr ${ }^{5}$
}

\begin{abstract}
There is now good evidence that cytokines and growth factors are key factors in tissue repair and often exert anti-infective activities. However, engineering such factors for global use, even in the most remote places, is not realistic. Instead, we propose to examine how such factors work and to evaluate the reparative tools generously provided by 'nature.' We used two approaches to address these objectives. The first approach was to reappraise the internal capacity of the factors contributing the most to healing in the body, i.e., blood platelets. The second was to revisit natural agents such as whey proteins, (honey) bee venom and propolis. The platelet approach elucidates the inflammation spectrum from physiology to pathology, whereas milk and honey derivatives accelerate diabetic wound healing. Thus, this review aims at offering a fresh view of how wound healing can be addressed by natural means.
\end{abstract}

Keywords: Wound, Diabetes, Healing factors, Platelets, Whey proteins, Propolis, Bee venom

\section{Background}

Wounds occur on multiple occasions during one's lifetime. Although they are less visible than external wounds, internal wounds frequently occur at the vascular surface. Such vascular attrition must be repaired to avoid bleeding and fluid loss from the vessels to tissues. The mucosae are also exposed to wounds that occasionally result in bleeding and/or infection. Additionally, organs can suffer wounds caused by external insults (weapons, surgery) or internal disorders (disease). Overall, wounds may be clear (surgical) or complex, clean or soiled, and aseptic or septic. Wounds may occur occasionally or frequently (recurrent) and may be acute or chronic. Chronic wounds are often associated with a patient's inability to sufficiently (correctly) heal and clear the source or cause of the attrition, such as in chronic infections or metabolic disorders. Metabolic disorders such as diabetes, which can result in infections and chronic wounds, are multifactorial. It has been estimated that nearly $9 \%$ of the global population is affected by diabetes, and diabetes is a leading cause of a chronic type of wound with vascular participation that is often infected and exhibits poor healing $[1,2]$. Thus, with an estimated worldwide population

\footnotetext{
* Correspondence: ogarraud@ints.fr

${ }^{1}$ GIMAP-EA3064, Faculty of medicine of Saint-Etienne, University of Lyon, 42023 Saint-Etienne, France

${ }^{2}$ National Institute for Blood Transfusion, 75015 Paris, France

Full list of author information is available at the end of the article
}

of 7.3 billion, nearly one billion people are likely to suffer acute and/or chronic wounds (in the USA, 6.5 million people suffer from chronic wounds) [3]. Therefore, for multiple reasons, hundreds of individuals present with skin/tissue attrition and hundreds more have organ lesions. Poverty, poor sanitation, malnutrition, insect bites, and envenomation, may either cause wounds or aggravate their consequences [4].

Healing is a complex process that evolves in phases and involves numerous key cellular and molecular players and frequently, because many wounds create breaches of the microvasculature, coagulation effectors [5]. Inflammation is now regarded as an initiator of healing, as long as the inflammation is contained and does not escape regulatory mechanisms and become pathologic. Wound repair is classically viewed as a four-step process: i) hemostasis; ii) inflammation; iii) cell proliferation/granulation; and iv) remodeling/maturation. The time frames for each step in the process are 1-3 days, 3-20 days, 7-40 days and 40 days to 2 years, respectively, with overlaps in subprocesses. If a wound is cutaneous, after the bleeding has stopped, the skin is temporarily thin, then consists of stronger, tightening skin tissue; in the final phase, the skin tissue is restored (a schematic of the process is presented in Fig. 1). Table 1 further presents the major cellular and molecular actors in the healing stages. 


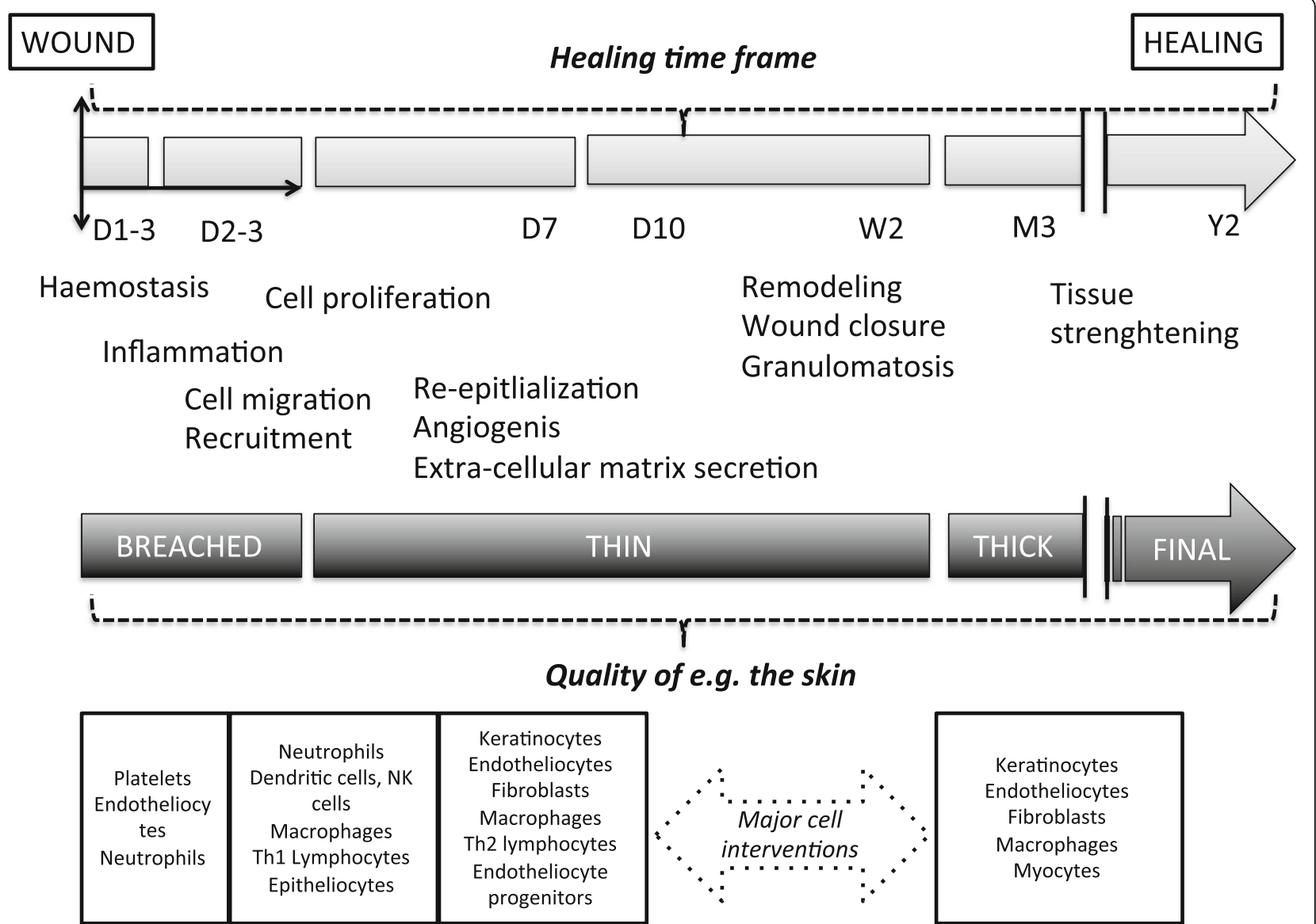

Fig. 1 Cartoons - from top to bottom-: i) The healing time frame expressed in days (D), weeks (W) and years (Y); ii) The main cell ant tissue events; iii) the quality of the skin; iv) the major cell and cell subsets involved (partly inspired by Ref [84])

Importantly, because conventional health care is not accessible everywhere or, when it is, is not made available to everyone because of the cost, the majority of the world's population commonly resorts to traditional medicines with various outcomes and often at the expense of imposing a superinfection. There is now good evidence

Table 1 Molecular factor essential to healing [84-87]

\begin{tabular}{ll}
\hline CYTOKINES, CHEMOKINES, & MATRIX GLYCOPROTEINS \\
GROWTH FACTORS & - Collagen \\
- IL-8 & - Fibrin \\
- SDF-1 & - Fibronectin \\
- VEGF-a & - Vitronectin \\
- PDGF & -Tenascin \\
- MCP-1 & ENZYMES and INHIBITORS \\
- IGF-1 & - a2-macroglobulin \\
- EGF-1 & - MMP-1,2,3,9 \\
- Keratinocyte growth factor & - TIMPs \\
- Angiopoietin-1 & - ACE \\
- MIP-1 & - Serine Proteases : urokine-type \\
- a-, $\beta$-erythropoietin & plasminogen activator \\
- GM-CSF & - Cathepsin G, \\
- FGF-2 & - Neutrophil elastase \\
OTHERS & - NO antagonists \\
- Complement factors & \\
\hline
\end{tabular}

that cytokines and growth factors are key actors in tissue repair and often exert anti-infective activities. However, engineering such factors for global use, particularly in the most remote places, is not realistic. We propose instead to examine how such factors work and to evaluate the reparative tools generously provided by 'nature.' We used two approaches to address these objectives. The first approach was to assess the internal capacity of the factors contributing the most to healing in the body, i.e., blood platelets. The second approach was to evaluate natural agents such as whey proteins from milk (and particularly from camels), (honey) bee venom and propolis.

\section{Blood platelets as healing factors}

Blood platelets are small elements derived from the fragmentation of megakaryocytes. Despite being nonnucleated, platelets can exert a number of essential functions [6, 7]. Platelets are primarily acknowledged as being essential to primary hemostasis and coagulation. Physiologically, platelets patrol along the vascular arborescence and repair injured vascular endothelium, which is considered a healing function [8]. The 
hemostatic functions of platelets (adhesion, activation, aggregation, and the recruitment of other platelets and leukocytes) are mediated by a number of specific receptors that bind to ligands on the sub-endothelial structure after vessel attrition (such as fibrinogen, collagen, vWF, etc.), on other platelets, and on leukocytes (integrins). However, the majority of such structures can also serve as ligands for numerous infectious pathogens (viruses, bacteria, parasites and fungi). Thus, platelets play a central role during tissue attrition (wounding) because they assist in hemostasis, innate immunity, anti-infection activity, inflammation and the secretion of a myriad of factors (including growth factors for stimulating the production of blood cells in bone marrow, chemokines to attract innate immune cells, reparative cytokines, and other biological response modifiers (BRMs) with a variety of functions) [9-11].

It is now understood that the essential function of platelets is to detect danger signals that are delivered by two principal types of warning systems: 1) External lesions. The archetype of this system is a vascular wound exposed to the surface (skin, muscle, and vessel), but this type also comprises sensing infectious agents with differential responses based on whether an agent is highly pathogenic, less pathogenic or not pathogenic [12, 13]; 2) Internal danger signals that activate platelets. The archetype of this system is the sensing of vascular erosion/attrition due to shear stresses inflicted by globules flowing into microscopic vessels that are half the size of such globules $[14,15]$. This type of warning can also occur in several other types of tissue and organ attrition caused by a chronic infection, so-called auto-inflammatory processes, etc. [16]. When patrolling along the vasculature (platelets are essentially circulating cell elements), platelets sense danger. The first danger situation that is sensed is vascular endothelial attrition. Platelets adhere to the injured vascular endothelium, undergo activation and secrete factors that are stored in abundance within granules (these factors are derived from megakaryocytes or absorbed from the plasma and eventually are secreted by the platelets). Platelets are loaded with healing and repairing factors, such as PDGF, EGF, VEGF, TGF- $\beta$, TF, etc., and with growth factors as well as cytokines and chemokines that mobilize bone marrow progenitor cells, which are attracted to the lesion sites and also secrete repairing factors [17-19]. Platelets have two main cell partners: endotheliocytes and leukocytes (platelets engage in very complex relationships with leukocyte subsets both physiologically and pathophysiologically; for reviews, see $[9,18,19])$. Approximately $10 \%$ of the platelet count is used daily to perform repairs and fix the pathophysiological alterations of the vascular endothelium due to shear stress inflicted by circulating cells and blood pressure.
Platelets are currently being evaluated as a therapeutic approach beyond their seminal role in assisting in hemostasis (platelet component transfusion) [20] and can be used in several forms. Autologous platelet-rich plasma is commonly injected in altered or injured tissues; regular protocols have been established to repair tendons, cartilage, bone, joints, muscle and soft tissues (including cardiac tissue), and the retina [21-25]. Platelet gels or glues come from two major sources: autologous and allogeneic [26, 27]. Platelet gels/glues are also used in sports medicine and traumatology, dental and ophthalmic surgery. Platelet preparations are also used in facial surgery, including aesthetic surgery [28]. Side effects, such as blood-borne infections, are still possible but the risk of side effects is mitigated when the platelets are autologous. When platelets are derived from blood donors, the preparations can benefit from pathogen reduction technologies (complementing labwork testing that assesses negativity for principal infectious markers in the product) [29]. The therapeutic factors in platelet preparations are the same as those in fresh platelets and are dominated by VEGF and TGF- $\beta$. Platelet repairing factors have been proven to have healing activity along with anti-inflammatory and anti-infectious activities [30]. Experimental findings have suggested a potential use of platelets or platelet preparations for ulcerative wounds with vascular participation and infections, such as gastric ulcers [31] and diabetes-related wounds [32]. Although interesting data have been reported, and platelet therapy in treating diabetic foot ulcers is promising, more clinical trials are required.

Additionally, because platelets have hemostatic, proinflammatory (to initiate the late-phase angiogenesis and remodeling phases), anti-inflammatory and anti-infectious effects, these blood components or derivatives. Because of the medical and economic effects of diabetes worldwide and the easy access of platelets, especially autologous platelets, platelets may be a promising avenue for the treatment of diabetes-associated wounds. However, platelet therapy mandates that safety and quality processes be strictly followed; such adherence may not be easy to fulfill in areas where diabetes occurs very frequently but transfusions are not yet optimized, as is the case in almost every developing country. Therefore, other natural alternatives must be considered.

\section{Healing properties of un-denatured whey protein in diabetic models}

The ability of animals to repair wounds after an injury is critical for survival [33]. A multitude of cellular events, such as cell proliferation, cell migration, contraction, extracellular matrix degradation and synthesis, must occur to achieve wound closure and the regeneration of the injured dermis [34]. These events rely on the 
temporal expression and activation of a variety of proteins such as growth factors, cytokines and matrix metalloproteinases [35]. The identification of dietary proteins that enhance skin repair contributes to the understanding of the wound-healing process and to therapeutic design. Whey protein is thought to be the highest quality protein available, as compared to other proteins, such as ovalbumin, casein, beef meat, or soy. Whey protein contains all the essential and non-essential amino acids and is an excellent source of glutamine and branched-chain amino acids, which are necessary for cell growth [36]. Thus, whey contains high levels of amino acids that are important for wound healing. These amino acids include arginine, glycine, and, in particular, the branch-chained amino acids leucine, isoleucine and valine, which are essential to promoting the healing of bones, skin, and muscle tissues. Another amino acid, proline, aids in the production of collagen, heals cartilage and strengthens joints, tendons and cardiac muscle.

Various spatial arrangements of amino acids in whey protein influence immune responses in different ways [36]. Therefore, it has been hypothesized that unique amino acid groups or peptides derived from whey proteins after ingestion can have significant immunomodulatory activities. Bioactive components include lactoferrin, lysozyme, lactoperoxidase, glycomacropeptide, alphalactalbumin, bovine serum albumin, various growth factors and immunoglobulins (Igs). Many of these components possess immunobiological properties. Lactoferrin exhibits anticancer, antiviral, antibacterial, and antifungal activity. Lactoferrin plays active roles in iron transport and in the cytotoxic defenses of neutrophils and scavenges free iron and associated oxygen radicals [37]. Un-denatured whey protein has been shown to be a potent inducer of glutathione, thereby reducing cellular damage and improving intracellular function [38]. Glutathione is a potent intracellular tripeptide that vigorously binds damaging free radical molecules that would otherwise harm the cell. During the inflammatory phase, the release of oxygen radicals by leukocytes, the subsequent lipid peroxidation of cellular and organelle membranes, the disruption of the intracellular matrix, and the alteration of important protein enzymatic processes cause tissue damage [37]. The generation of oxygen radicals is normally mitigated by the presence of adequate endogenous antioxidant defenses [37]. In diabetes, oxidative stress is increased by a system in which the rate of free radical production is enhanced and/or endogenous antioxidant mechanisms are impaired. Oxidative-stressinduced free radicals have been found to be key players in the pathophysiology of diabetes mellitus and neurodegenerative diseases [39]. Many studies have confirmed that glutathione, which is increased by dietary whey protein, is a powerful antioxidant? The efficiency of cysteine in increasing glutathione levels is greater when this amino acid is delivered as whey protein rather than as free cysteine [40-42].

Animals fed un-denatured whey protein display accelerated wound healing. Whey protein has been reported to act at the intersection of inflammation and proliferation (Fig. 1) because some components in whey protein exert mitogenic activity on lymphocytes [42]. Being rich in cysteine, whey protein seems to control lymphocyte functions; both the conventional $\mathrm{T}$ (Th1)lymphocytes, which are prone to stimulate fibroblasts, and B-lymphocytes appear to be targeted by this amino acid. Regarding B-lymphocytes, at least in experimental models, whey protein influences immunoglobulin (Ig) production in the spleen [42]. B-lymphocytes are impaired in animals with experimentally induced diabetes, and experimentally restoring normal B-cell physiology has been shown to be beneficial [42, 43]. Whey protein is also a source of abundant levels of arginine, an important factor in sustaining the activity of natural killer (NK) cells, which secrete appreciable amounts of cytokines that are active in cell proliferation, such as interferon- $\gamma$.

Whey protein is able to decrease the effects of oxygen radicals and lipid peroxidation by increasing the antioxidant glutathione and, thereby, stimulating epithelialization and the proliferation of fibroblasts as well as increasing the secretion of both pre-inflammatory and postinflammatory cytokines. Furthermore, un-denatured whey protein provides proline, which is important factor that assists in collagen production $[44,45]$ and aids in the normal development of collagen fibrils in a wounded region. It is accepted that un-denatured whey proteins can accelerate wound healing in animals with experimentally induced diabetes.

In addition to decreasing lipid peroxidation and increasing lymphocyte proliferation and Ig production, glutathione-which is abundant in un-denatured whey protein-also increases the numbers of mast cells and fibroblasts, which take part in remodeling.

Whey protein for medical use can be obtained from different animals. Camel milk in particular has been studied for this purpose. Camel-milk-extracted whey protein enhances normal inflammatory responses during cutaneous wound healing in experimentally induced diabetic rats, thus confirming the essential role of inflammation in the healing process [46]. After oral supplementation with whey protein, diabetic mice and rats have been tested for B- and T-lymphocyte functions [47]. Supplemented animals display enhanced cell proliferation and chemotactic capacity; these functions are associated with high levels of CCL21, CXCL12, MIP1a, MIP2, KC, CXCL3 and TGF- $\beta$ in the whey extracts $[47,48]$. Providing a whey protein-enriched diet 
to diabetic animals also favors the rescue from apoptosis of long-lived macrophages present in wounds and an acceleration of the healing and closure of diabetic wounds [49]. Furthermore, a whey protein-enriched diet decreases the levels of $\beta$-defensins 2 and 3 associated with increased free radicals and diminished glutathione caused by experimental diabetes [50].

In summary, diabetes-induced ulcers, at least in experimental models, display impair profiles of proinflammatory/anti-inflammatory factors. This phenomenon is associated with a delay in the resolution phase of the healing process because aberrant messages are sent to T- and B-lymphocytes and macrophages, thereby impairing re-epithelialization and remodeling (which is normally carried out by platelets, macrophages, epitheliocytes and fibroblasts and represents the final phase of healing-associated physiological inflammation). Oral supplementation with appropriate amino acids that have a strong tropism for immune cells involved in inflammation and healing (such as lymphocytes and macrophages) has been shown to reverse the delay in closing experimentally inflicted wounds mimicking diabetic ulcers. Whey proteins, especially those from camel milk, have interesting potential in treating patients suffering diabetic ulcers. Whey proteins are available or can be made available in a native form in a number of countries and can be synthesized, hopefully, at a reasonable price. This may be an interesting avenue to complement the local treatment of wounds.

\section{Topical (honey) bee venom and propolis constituents to accelerate wound healing in diabetes \\ Bee propolis and wound healing properties}

Many facets of wound healing under redox control require a delicate balance between oxidative stress and antioxidants. Whereas normal physiological wound healing depends on low levels of ROS and oxidative stress, overexposure to oxidative stress leads to impaired wound healing. Antioxidants have been postulated to help control wound oxidative stress and thereby accelerate wound healing. Many antioxidants are available over the counter or by prescription, but only one, Medihoney ${ }^{\mathrm{mm}}$, is FDA-approved specifically to treat wound healing $[51,52]$; this product is made from honey, as its name implies. However, there is a lack of understanding regarding the molecular mechanisms of action for such honey-based, anti-oxidative topical gels.

There is an increasing interest in the use of natural products in modern medicine as part of disease and patient management. Natural products have been widely used to dissect the basic mechanisms underlying fundamental questions in the life sciences and also as clinical therapeutics. Bee products are natural and have diverse applications in medical fields for the treatment of various diseases. The identification of bee products that may enhance skin repair can contribute to a better understanding of the wound healing process and generate a new strategy to combat chronic wounds. Bee venom and propolis, which possess considerable antioxidant capacities, are important components of bee-based products. Propolis has been reported to have a broad spectrum of biological and pharmacological properties, including antimicrobial, antioxidant, anti-inflammatory, immunomodulatory $[53,54]$, antiulcer, hepatoprotective, cardioprotective, and neuroprotective actions [55, 56]. It is important to note that propolis has been found to exert profound anti-infective actions and has been used in topical gels and in dentistry [57]. However, the chemical composition and beneficial properties of propolis vary greatly depending on phytogeographical area, seasonal collection time, and botanical sources. Depending on its exact composition (and origin), propolis may also exhibit powerful local antibiotic and antifungal properties [58-61].

Propolis possesses remarkable anti-cancer properties [62-64]. Experimental studies in cancer have revealed specific modes of actions of propolis. Propolis induces cell cycle arrest and apoptosis and decreases the expression of growth and transcription factors (including NF- $\mathrm{kB}$ ) in pre-clinical models of human breast cancer. Notably, caffeic acid phenethyl ester down-regulates the $m d r-1$ gene, which is considered responsible for the resistance of cancer cells to certain chemotherapeutic agents.

In total, more than 300 constituents have been identified in propolis samples, whereas the biological activity of propolis has been mainly attributed to a handful of substances, including flavonoids, terpenes, caffeic acid, ferulic acid, cumaric acid and esters. Propolis is characterized by many diverse activities, but only some of these activities have been substantiated by clinical and experimental evidence [65].

Propolis is believed to decrease tissue degeneration and has been proven to be effective in treating skin burns [66, 67].

With specific reference to wound healing, propolis has recently been demonstrated to accelerate wound healing in different animal models that mimic diabetic wounds $[68,69]$. We (and others) have sought to explore the mechanisms by which propolis can ameliorate the diabetic condition. Propolis constituents and active metabolites had been well characterized in terms of chemistry [70]. The oral supplementation of diabetic mice with propolis has been found to restore the proliferation and chemotactic capacity of B- and T-lymphocytes toward chemokines by interfering with the lipid inflammatory pathway [71]. The topical application of propolis has further been shown to enhance the cutaneous wound healing of diabetic ulcers experimentally induced in mice by promoting TGF-B/SMAD-mediated collagen 
production [72]. Therefore, propolis may have two potential properties in diabetes: per os to modify lipid dysregulation and locally to accelerate tissue remodeling. This possibility remains to be further explored through studies including randomized controlled trials.

\section{Bee venom and wound healing}

In addition to the honey derivative propolis, there has traditionally been interest in another honeybee product: venom. Bee venom therapy is one of the most traditional complementary and alternative therapies and has long been believed to be effective in the treatment of many diseases, including rheumatic arthritis, bursitis, tendinitis, shingles (herpes zoster), multiple sclerosis and other autoimmune diseases, wounds, gout, burns, infections, and even cancer. This approach is primarily expected to relieve pain and inflammation and restore normal functions [73-75]. Although bee venom therapy may be a promising alternative for the treatment of chronic pain, in contrast to honey propolis, it has not been approved as being effective and safe by the worldwide food and drug authorities.

Honeybee venom is composed of melittin, phospholipase A2, apamin, mast cell degranulating peptide and several bioactive amines, such as histamine and epinephrine, among other components. Melittin and phospholipase A2 are the two major components of bee venom $(40-60 \%$ and $15-20 \%$, respectively [76]). These components are generally thought to play an important role in the induction of the irritation and allergic reactions associated with bee stings. The injection of bee venom has been reported to evoke hyperalgesia and a sharp pricking sensation followed by tonic pain lasting for a few minutes up to $1-2 \mathrm{~h}$.

However, there is conflicting evidence in the literature to suggest that bee venom may also exert antiinflammatory and anti-nociceptive effects [77, 78]. One group claiming that melittin has certain antiinflammatory effects has provided interesting evidence of an influx of cytokines and nitric oxide caused by bee venom, which have been postulated to play important roles in mediating the cell recruitment and activation necessary to balance inflammation/anti-inflammation and repair tissue damage [79]. Recently, it has further been demonstrated that bee venom can experimentally accelerate wound healing in diabetic mice by suppressing activating transcription factor-3 (ATF-3) and inducible nitric oxide synthase (iNOS)-mediated oxidative stress. Evidence has also been obtained that bee venom can help recruit bone marrow-derived endothelial cells, thus accelerating re-epithelialization and tissue remodeling [80].

\section{Conclusions}

There are distinct avenues to pursue when considering certain 'gifts' of 'nature' as potential universal drugs. One must decipher mode(s) of action at the cellular and molecular levels (most natural products exert antioxidant activities that have strong inflammatory/anti-inflammatory potential). One must also understand how to use these 'gifts' to provide care and cure and not cause harm. In other words, it must be determined that the benefit/risk is highly favorable. Finally, one must test the products in registered trials and evaluate them in terms of their benefits compared to commonly accepted treatments. The use of well-characterized 'natural' antioxidants has interesting potential in countries with developing economies because these products can be made available at a low cost if the natural resource is abundant. Products of natural origin must thus be taken into consideration along with current conventional therapies in regenerative medicine [81] as well as novel cell therapies, such as promising mesenchymal cell therapy $[82,83]$.

\section{Funding}

The projects' lead authors were funded in part by the National Plan for Science, Technology and Innovation (MAARIFAH), King Abdulaziz City for Science and Technology, Kingdom of Saudi Arabia, Award number (12-BIO2609-02). Publication charge was funded by the 12-BIO2609-02 program (King Saudi University).

\section{Availability of data and materials N/A.}

\section{Authors' contributions}

OG drafted the manuscript; WNH and GB were PIs of most research projects covered in this review article; WNH and GB reviewed the manuscript. All authors read and approved the final manuscript.

\section{Competing interests}

The authors declare that they have no competing interests.

\section{Consent for publication}

N/A.

Ethics approval and consent to participate

N/A.

\section{About this supplement}

This article has been published as part of BMC Immunology Volume 18 Supplement 1, 2017. Systems Immunology \& Immunolnformatics. The full contents of the supplement are available online https://bmcimmunol. biomedcentral.com/articles/supplements/volume-18-supplement-1.

\section{Publisher's Note}

Springer Nature remains neutral with regard to jurisdictional claims in published maps and institutional affiliations.

\section{Author details \\ ${ }^{1}$ GIMAP-EA3064, Faculty of medicine of Saint-Etienne, University of Lyon, 42023 Saint-Etienne, France. ${ }^{2}$ National Institute for Blood Transfusion, 75015 Paris, France. ${ }^{3}$ Bioproducts Research Chair, Department of Zoology, College of Science, King Saud University, Riyadh, Saudi Arabia. ${ }^{4}$ Botany Department, Faculty of Science, Beni-Suef University, Beni-Suef, Egypt. ${ }^{5}$ Laboratory of Immunology and Molecular Physiology, Zoology Department, Faculty of Science, Assiut University, 71516 Assiut, Egypt.}

Published: 21 June 2017

\section{References}

1. van Koppen CJ, Hartmann RW. Advances in the treatment of chronic wounds: a patent review. Expert Opin Ther Pat. 2015;25:931-7. 
2. Garwood CS, Steinberg JS. What's new in wound treatment: a critical appraisal. Diabetes Metab Res Rev 2015. doi:10.1002/dmrr.2747.

3. Sen CK, Gordillo GM, Roy S, Kirsner R, Lambert L, Hunt TK, Gottrup F, Gurtner GC, Longaker MT. Human skin wounds: a major and snowballing threat to public healt ad economy. Wound Repair Regen. 2009;17:763-71.

4. Jaspers L, Colpani V, Chaker L, van der Lee SJ, Muka T, Imo D, Mendis S, Chowdhury R, Bramer WM, Falla A, Pazoki R, Franco OH. The global impact of non-communicable diseases on households and impoverishment: a systematic review. Eur J Epidemiol. 2015;30:163-88.

5. LeBert DC, Huttenlocher A. Inflammation and wound repair. Semin Immunol. 2014;26:315-20.

6. Garraud O, Cognasse F. Are platelet cells? and if yes, are they immune cells? Front Immunol. 2015;6:70. doi:10.3389/fimmu.2015.00270.

7. Lam FW, Vijayan KV, Rumbaut RE. Platelets and their interactions with other immune cells. Compr Physiol. 2015:5:1265-80.

8. de Groot PG, Urbanus RT, Roest M. Platelet interaction with the vessel wall. Handb Exp Pharmacol. 2012:210:87-110.

9. Rossaint J, Zarbock A. Platelets in leukocyte recruitment ad function. Cardiovasc Res. 2015:107:386-95.

10. Jenne CN, Kubes P. Platelets in inflammation and infection. Platelets. 2015; 26:286-92.

11. Garraud O, Hamzeh-Cognasse H, Cognasse F. Platelets and cytokines: How and why? Transfus Clin Biol. 2012;19:104-8.

12. Cognasse F, Nguyen KA, Damien P, McNichol A, POzzetto B, HamzehCognasse $\mathrm{H}$, Garraud $\mathrm{O}$. The inflammatory role of platelets via their TLRs and Siglec receptors. Front Immunol 6:83. doi:10.2289/fimmu.2015.00083.

13. Kapur R, Zufferey A, Boilard E, Semple JW. Nouvelle cuisine: platelets served with inflammation. J Immunol. 2015;194:5579-87.

14. Casa LD, Deaton DH, Ku DN. Role of high shear rate in thrombosis. J Vasc Surg. 2015;61:1068-80.

15. Cosemans JM, Angelillo-Scherrer A, Mattheij NJ, Heemskerk JW. The effects of arterial flow on platelet activation, thrombus growth, and stabilization. Cardiovasc Res. 2013;99:342-52.

16. Boilard E, Blanco P, Nigrovic PA. Platelets: active players in the pathogenesis of arthritis and SLE. Nat Rev Rheumatol. 2012;8:534-42.

17. Nurden AT. Platelets, inflammation and tissue regeneration. Thromb Haemost. 2011;105 Suppl 1:S13-33.

18. Ed Rainger G, Chimen M, Harrison MJ, Yates CM, Harrison P, Watson SP, Lordkipanidzé M, Nash GB. The role of platelets in the recruitment of leukocytes during vascular disease. Platelets. 2015;26:507-20.

19. Gros A, Ollivier V, Ho-Tin-Noé B. Platelets in inflammation: regulation of leukocyte activities and vascular repair. Front Immunol. 2015;5:678. doi:10.3389/fimmu.2014.00678.

20. Kaufman RM, Djulbegovic B, Gernsheimer T, Kleinman S, Tinmouth AT, Capocelli KE, Cipolle MD, Cohn CS, Fung MK, Grossman BJ, Mintz PD, O'Malley BA, Sesok-Pizzini DA, Shander A, Stack GE, Webert KE, Weinstein R, Welch BG, Whitman GJ, Wong EC, Tobian AA, AABB. Platelet transfusion: a clinical practice guideline from the AABB. Ann Intern Med. 2015;162:205-13.

21. Davis VL, Abukabda AB, Radio NM, Witt-Enderby PA, Clafshenkel WP, Cairone JV, Rutkowski JL. Platelet-rich preparations to improve healing. Part I: workable options for every size practice. J Oral Implantol. 2014;40:500-10.

22. Davis VL, Abukabda AB, Radio NM, Witt-Enderby PA, Clafshenkel WP, Cairone JV, Rutkowski JL. Platelet-rich preparations to improve healing Part II: platelet activation and enrichment, leukocyte inclusion, and other selection criteria. J Oral Implantol. 2014:40:511-21.

23. Spartalis E, Tomos P, Moris D, Athanasiou A, Markakis C, Spartalis MD, Troupis T, Dimitroulis $D$, Perrea D. Role of platelet-rich plasma in ischemic heart disease: an update on the latest evidence. World J Cardiol. 2015;7:665-70.

24. Borrione P, Gianfrancesco AD, Pereira MT, Pigozzi F. Platelet rich plasma in muscle healing. Am J Phys Med Rehabil. 2010;89:854-61.

25. Yin W, Qi X, Zhang Y, Sheng JXZ, Tao S, Xie X, Li X, Zhang C. Advantage of pure platelet rich plasma compared with leukocyte- and platelet rich plasma in promoting repair of bone defects. J Translat Med. 2016;14:e73.

26. Burnouf T, Goubran HA, Chen TM, Ou KL, El-Ekiaby M, Radosevic M. Bloodderived biomaterials and platelet growth factors in regenerative medicine. Blood Rev. 2013;27:77-89.

27. Burnouf T. Platelet gels. ISBT Sci Series. 2013;8:131-6.

28. Bhanot S, Alex JC. Current applications of platelet gels in facial plastic surgery. Facial Plast Surg. 2002;18:27-33.

29. Kwon SY, Kim IS, Bae JE, Kang JW, Cho YJ, Cho NS, Lee SW. Pathogen inactivation efficacy of Mirasol PRT System and Intercept Blood System for non-leucoreduced platelet-rich plasma-derived platelets suspended in plasma. Vox Sang. 2014;107:254-60.

30. Bao P, Kodra A, Tomic-Canic M, Golinko MS, Ehrlich PH, Brem H. The role of vascular endothelial growth factor in wound healing. J Surg Res. 2009;153:347-58.

31. Ma L, Elliott $S N$, Cirino G, Buret A, Ignarro LJ, Wallace JL. Platelets modulate gastric ulcer healing: role of endostatin and vascular endothelial growth factor release. Proc Natl Acad USA. 2001;98:6470-5.

32. Pietramaggiori G, Scherer SS, Mathews JC, Gennaoui T, Lancerotto L, Ragno G, Valeri R, Orgill DP. Quiescent platelets stimulate angiogenesis and diabetic wound repair. J Surg Res. 2010;160:169-77.

33. Ashcroft GS, Horan MA, Ferguson MW. The effects of ageing on cutaneous wound healing in mammals. J Anat. 1995;187:1-26.

34. Singer AJ, Clark RA. Cutaneous wound healing. N Engl J Med. 1999;341:738-46.

35. Bradshaw $A D$, Sage $E H$. Regulation of cell behavior by matricellular proteins. In: Lanza R, Langer R, Vacanti J, editors. Principles of tissue engineering. San Diego CA: Academic; 2000.

36. Belokrylov GA, Popova OYA, Molchanova IV, Sorochiniskaya El, Anokbina W. Peptides and their constituent amino acids influence the immune response and phagocytosis in different ways. Int J Immunopharmacol. 1992;14:1285-92.

37. Wong CW, Watson DL. Immunomodulatory effects of dietary whey proteins in mice. J Dairy Res. 1995;62:359-68.

38. Bounous $G$, Batist PG. Immunoenhancing property of dietary whey protein in mice: role of glutathione. Clin Invest Med. 1989;12:154-61.

39. Niki E, Yamamoto Y, Komuro E, Sato K. Membrane damage due to lipid peroxidation. Am J Clin Nutr. 1991;53:201S-5S.

40. Bounous G, Kongshavn PAL, Gold P. The immunoenhancing property of dietary whey protein concentrate. Clin Invest Med. 1988;11:271-8.

41. Low PP, Rutherfurd K, Gill HS, Cross ML. Effect of dietary whey protein concentrate on primary and secondary antibody responses in immunized BALB/c mice. Int Immunopharmacol. 2003;3:393-401.

42. Hsu WT, Tsai LY, Lin SK, Hsiao K, Chen BH. Effects of diabetes duration and glycemic control on free radicals in children with type 1 diabetes mellitus. Ann Clin Lab Sci. 2006;36:174-8.

43. Badr BM, Moustafa NA, Eldien HM, Mohamed AO, Ibrahim HM, El-Alaimy IA, Mahmoud MH, Badr G. Increased levels of type 1 interferon in a type 1 diabetic mouse model induce the elimination of B cells from the periphery apoptosis and increase of their retention in the spleen. Cell Physiol Biochem. 2015;35:137-47.

44. Gauthier SF, Pouliot Y, Saint-Sauveur D. Imunomodulatory peptides obtained by the enzymatic hydrolysis of whey proteins. Int Dairy J. 2006:16:1315-23.

45. Ebaid H, Ahmed OM, Mahmoud AM, Ahmed RR. Limiting prolonged inflammation during proliferation and remodeling phases of wound healing in streptozotocin-induced diabetic rats supplemented with camel undenatured whey protein. BMC Immunol. 2013;14:31. doi:10.1186/14712172-14-31.

46. Badr G, Mohany M, Metwalli A. Effects of undenatured whey protein supplementation on CXCL12- and CCL21-mediated B and T cell chemotaxis in diabetic mice. Lipids Health Dis. 2011;10:203. doi:10.1186/ 1476-511X-10-203.

47. Badr G, Ebaid H, Mohany M, Abuelsaad AS. Modulation of immune cell proliferation and chemotaxis towards CC chemokine ligand (CCL)-21 and CXC chemokine ligand (CXCL)-12 in undenatured whey protein-treated mice. J Nutr Biochem. 2012;23:1640-6.

48. Badr G, Badr BM, Mahmoud MH, Mohany M, Rabah DM, Garraud O. Treatment of diabetic mice with undenatured whey protein accelerates the wound healing process by enhancing the expression of MIP-1a, MIP-2, KC, CX3CL1 and TGF- $\beta$ in wounded tissue. BMC Immunol. 2012;13:32. doi:10. 1186/1471-2172-13-32

49. Badr G. Supplementation with un-denatured whey protein during diabetes mellitus improves the healing and closure of diabetic wounds through the rescue of functional long-lived wound macrophages. Cell Physiol Biochem. 2012:29:571-82

50. Badr G. Camel whey protein enhances diabetic wound healing in a streptozotocin-induced diabetic mouse model: the critical role of $\beta$-Defensin-1, -2 and -3. Lipids Health Dis. 2013;12:46. doi:10.1186/14712172-13-32.

51. Fitzmaurice SD, Sivamani RK, Isseroff RR. Antioxidant therapies for wound healing: a clinical guide to currently commercially available products. Skin Pharmacol Physiol. 2011;24:113-26. 
52. De Vecchi E, Drago L. Propolis' antimicrobial activity: what's new? Infect Med. 2007:15:7-15.

53. Ansorge S, Reinhold D, Lendeckel U. Propolis and some of its constituents down-regulate DNA synthesis and inflammatory cytokine production but induce TGF-beta1 production of human immune cells. Z Naturforsch C. 2003:58:580-9

54. Simões LM, Gregório LE, Da Silva Filho AA, de Souza ML, Azzolini AE, Bastos JK, Lucisano-Valim YM. Effect of Brazilian green propolis on the production of reactive oxygen species by stimulated neutrophils. J Ethnopharmacol. 2004:94:59-65.

55. Sun F, Hayami S, Haruna S, Ogiri Y, Tanaka K, Yamada Y, Ikeda K, Yamada H, Sugimoto $\mathrm{H}$, Kawai $\mathrm{N}$, Kojo $\mathrm{S}$. In vivo antioxidative activity of propolis evaluated by the interaction with vitamins $C$ and $E$ and the level of lipid hydroperoxides in rats. J Agric Food Chem. 2000;48:1462-5.

56. Farooqui T, Farooqui AA. Beneficial effects of propolis on human health and neurological diseases. Front Biosci. 2012;4:779-93.

57. Duarte S, Rosalen PL, Hayacibara MF, Cury JA, Bowen WH, Marquis RE, Rehder VL, Sartoratto A, Ikegaki M, Koo H. The influence of a novel propolis on mutans streptococci biofilms and caries development in rats. Arch Oral Biol. 2006;51:15-22.

58. Orsi RO, Sforcin JM, Funari SR, Bankova V. Effects of Brazilian and Bulgarian propolis on bactericidal activity of macrophages against Salmonella Typhimurium. Int Immunopharmacol. 2005;5:359-68.

59. Da Silva Cunha IB, Salomão K, Shimizu M, Bankova VS, Custódio AR, de Castro SL, Marcucci MC. Antitrypanosomal activity of Brazilian propolis from Apis mellifera. Chem Pharm Bull (Tokyo). 2004;52:602-4.

60. De Castro SL, Higashi KO. Effect of different formulations of propolis on mice infected with Trypanosoma cruzi. J Ethnopharmacol. 1995;46:55-8.

61. Prytzyk E, Dantas AP, Salomão K, Pereira AS, Bankova VS, De Castro SL, Neto FR. Flavonoids and trypanocidal activity of Bulgarian propolis. J Ethnopharmacol. 2003;88:189-93.

62. Sugimoto Y, Iba Y, Kayasuga R, Kirino Y, Nishiga M, Alejandra Hossen M, Okihara K, Sugimoto H, Yamada H, Kamei C. Inhibitory effects of propolis granular A P C on 4-(methylnitrosamino)-1-(3-pyridyl)-1-butanone-induced lung tumorigenesis in A/J mice. Cancer Lett. 2003;193:155-9.

63. Wu J, Omene C, Karkoszka J, Bosland M, Eckard J, Klein CB, Frenkel K. Caffeic acid phenethyl ester (CAPE), derived from a honeybee product propolis, exhibits a diversity of anti-tumor effects in pre-clinical models of human breast cancer. Cancer Lett. 2011;308:43-53.

64. Omene CO, Wu J, Frenkel K. Caffeic Acid Phenethyl Ester (CAPE) derived from propolis, a honeybee product, inhibits growth of breast cancer stem cells. Invest New Drugs. 2012;30:1279-88.

65. Ocakci A, Kanter M, Cabuk M, Buyukbas S. Role of caffeic acid phenethyl ester, an active component of propolis, against $\mathrm{NAOH}$-induced esophageal burns in rats. Int J Pediatr Otorhinolaryngol. 2006;70:1731-9.

66. Gregory SR, Piccolo N, Piccolo MT, Piccolo MS, Heggers JP. Comparison of propolis skin cream to silver sulfadiazine: a naturopathic alternative to antibiotics in treatment of minor burns. J Altern Complement Med. 2002:8:77-83

67. Hoşnuter M, Gürel A, Babuç̧u O, Armutcu F, Kargi E, Işikdemir A. The effect of CAPE on lipid peroxidation and nitric oxide levels in the plasma of rats following thermal injury. Burns. 2004;30:121-5.

68. Lotfy M, Badra G, Burham W, Alenzi FQ. Combined use of honey, bee propolis and myrrh in healing a deep, infected wound in a patient with diabetes mellitus. Br J Biomed Sci. 2006;63:171-3.

69. McLennan SV, Min D, Yue DK. Matrix metalloproteinases and their roles in poor wound healing in diabetes. Wound Pract Res. 2008;16:116-21.

70. Jerz G, Elnakady YA, Braun A, Jäckel K, Sasse F, Al Ghamdi AA, Omar MO, Winterhalter $\mathrm{P}$. Preparative mass-spectrometry profiling of bioactive metabolites in Saudi-Arabian propolis fractionated by high-speed countercurrent chromatography and off-line atmospheric pressure chemical ionization mass-spectrometry injection. J Chromatogr A. 2014;1347:17-29. doi:10.1016/j.chroma.2014.04.068.

71. Al Ghamdi A, Badr G, Hozzein WN, Allam A, Al-WAili NS, Al-Wadaan MA, Garraud O. Oral supplementation of diabetic mice with propolis restores the proliferation capacity and chemotaxis of B and T lymphocytes towards CCL21 and CXCL12 by modulating the lipid profile, the proinflammatory cytokine levels and oxidative stress. BMC Immunol. 2015; 16:54. doi:10.1186/s12865-015-0117-09.

72. Hozzein WN, Badr G, Al Ghamdi AA, Sayed A, Al-Waili NS, Garraud O. Topical application of propolis enhances cutaneous wound healing by promoting
TGF-beta/Smad-mediated collagen production in Streptozoin-induced Type I diabetic mouse model. Cell Physiol Biochem. 2015;37:940-54.

73. Chen J, Lariviere WR. The nociceptive and anti-nociceptive effects of bee venom injection and therapy: a double-edged sword. Prog Neurobiol. 2010;92:151-83.

74. Son DJ, Lee JW, Lee YH, Song HS, Lee CK, Hong JT. Therapeutic application of anti-arthritis, pain-releasing, and anti-cancer effects of bee venom and its constituent compounds. Pharmacol Ther. 2007;115:246-70.

75. Hu H, Chen D, Li Y, Zhang X. Effect of polypeptides in bee venom on growth inhibition and apoptosis induction of the human hepatoma cell line SMMC-7721 in vitro and Balb/c nude mice in vivo. J Pharm Pharmacol. 2006;58:83-9.

76. Kwon YB, Lee HJ, Han HJ, Mar WC, Kang SK, Yoon OB, Beitz AJ, Lee JH. The water-soluble fraction of bee venom produces antinociceptive and antiinflammatory effects on rheumatoid arthritis in rats. Life Sci. 2002:71:191-204.

77. Hamedani M, Mirshafiey A, Vatanpour H, Khorramizadeh MR, Saadat F, Berahmeh A, Hadji-Ghasemi F. In vitro assessment of bee venom effects on matrix metalloproteinase activity and interferon production. Iran J Allergy Asthma Immunol. 2005:4:9-14.

78. Hamedani M, Vatanpour H, Saadat F, Reza Khorramizaheh M, Mirshafiey A. Bee venom, immunostimulant or immunosuppressor? Insight into the effect on matrix metalloproteinases and interferons. Immunopharmacol Immunotoxicol. 2005;27:671-81.

79. Petricevich VL. Cytokine and nitric oxide production following severe envenomation. Curr Drug Targets Inflamm Allergy. 2004;3:325-32.

80. Badr G, Hozzein WN, Badr BM, Al Ghamdi A, Saad Eldien HM, Garraud O. Bee venom accelerates wound healing in diabetic mice by suppressing activating transcription factor-3 (ATF-3) and inducible nitric oxide synthase (iNOS)-mediated oxidative stress and recruiting bone marrow-derived endothelial progenitor cells. J Cell Physiol 2016. doi:10.1002/jcp.25328.

81. Mao AS, Mooney DJ. Regenerative medicine: current therapies and future directions. Proc Natl Acad Sci U S A. 2015;112:14452-9.

82. Cerqueira MT, Pirraco RP, Marques AP. Stem cells in skin wound healing: are we there yet? Adv Wound Care (New Rochelle). 2016;5:164-75.

83. Otero-Viñas M, Falanga V. Mesenchymal stem cells in chronic wounds: the spectrum from basic to advanced therapy. Adv Wound Care (New Rochelle). 2016:5:149-63.

84. O'Loughlin A, O'Brien T. Topical stem and progenitor cell therapy for diabetic foot ulcers, stem cells in clinic and research, Gholamrezanezhad A (Ed.), ISBN: 978-953-307-797-0, InTech, Available from: https:/www.intechopen.com/ books/stem-cells-in-clinic-and-research/topical-stem-and-progenitor-celltherapy-for-diabetic-foot-ulcers.

85. Kryczka J, Boncela J. Leukocytes: the double-edged sword in fibrosis. Mediators Inflamm. 2015, 652035. doi:10.1155/2015/652035.

86. Kreuger J, Phillipson M. Targeting vascular and leukocyte communication in angiogenesis, inflammation and fibrosis. Nat Rev Drug Discov. 2015. doi:10.1038/nrd.2015.2.

87. Santana P, Martel J, Lai HC, Perfettini JL, Kannellopoulos J, Young JD, Coutinho-Silva R, Ojcius DM. Is the inflammasome relevant for epithelial cell function? Microbes Infect. 2015. doi:10.1016/j.micinf.2015.10.007.

\section{Submit your next manuscript to BioMed Central and we will help you at every step:}

- We accept pre-submission inquiries

- Our selector tool helps you to find the most relevant journal

- We provide round the clock customer support

- Convenient online submission

- Thorough peer review

- Inclusion in PubMed and all major indexing services

- Maximum visibility for your research

Submit your manuscript at www.biomedcentral.com/submit
Biomed Central 